\title{
RESENHA/REVISIÓN/REVIEW
}

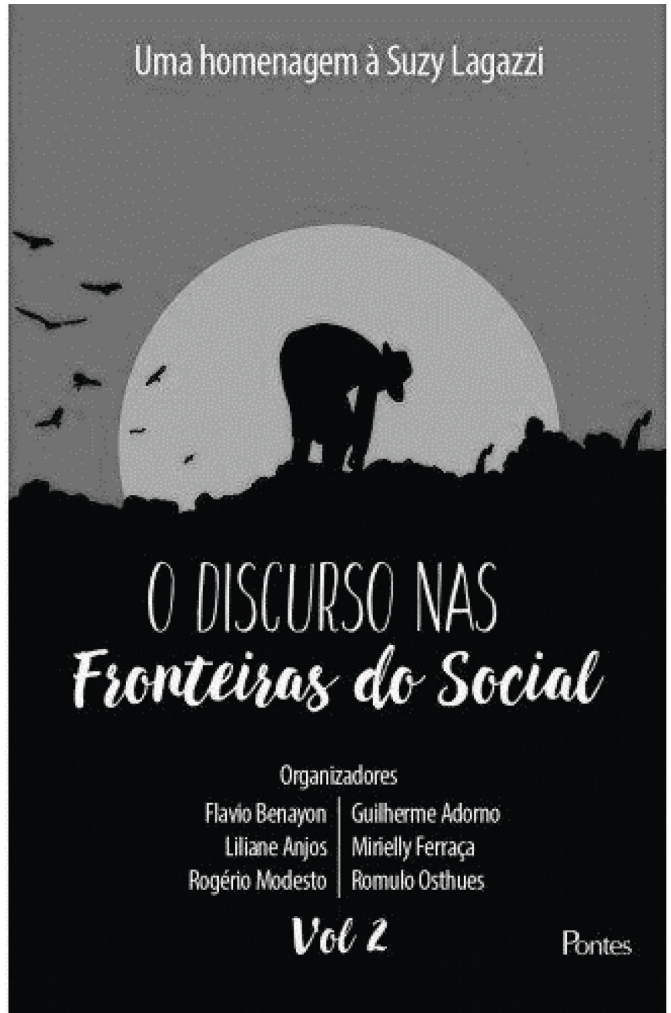

\section{A SINGULAR PRESENÇA DO DISCURSO NO BRASIL: DA HOMENAGEM À SUZY LAGAZZI}

\section{LA PARTICULAR PRESENCIA DEL DISCURSO EN BRASIL: DEL HOMENAJE A SUZY LAGAZZI}

THE SINGULAR PRESENCE OF DISCOURSE IN BRAZIL: FROM THE SUZY LAGAZZI TRIBUTE

Resenhado por:

Matheus França Ragievicz

Universidade Federal do Paraná

ADORNO, G.; MODESTO, R.; FERRAÇA, M.; BENAYON, F.; ANJOS, L.; OSTHUES, R.. (org.). O discurso nas fronteiras do social: uma homenagem à Suzy Lagazzi - volume 2. Campinas, SP: Pontes Editores, 2019. 363p.

\footnotetext{
Doutorando na área de concentração de Estudos Linguísticos pelo Programa de Pós-Graduação em Letras da Universidade Federal do Paraná (PPGLET/UFPR). Professor substituto de Língua Espanhola na Universidade Federal da FronteiraSul-campusRealeza.E-mail: matheusfrancar@gmail.com.
} 
O segundo volume da calorosa e afetuosa coletânea organizada em homenagem à Suzy Lagazzi, O discurso nas fronteiras do social, publicado junto ao primeiro volume em 2019, pela Pontes Editores, dá continuidade à demonstração da potência, genialidade e sutileza da pesquisadora em dar consequências à Análise de Discurso (AD) no Brasil. O modo encontrado pelos organizadores, Flavio Benayon, Liliane Anjos, Rogério Modesto, Guilherme Adorno, Mirielly Ferraça e Romulo Osthues, de promover o reconhecimento da produção científica e o trabalho da homenageada em prol da linguística brasileira, expressa-se na cuidadosa seleção de treze artigos que estão distribuídos nos eixos que contemplam os grandes empreendimentos teóricos de Lagazzi, a saber, $o$ político e o jurídico, a imbricação de diferentes materialidades significantes e, por último, resistência simbólica. Os autores que contribuem com a obra celebram sua relação de afeto, de amizade e de reconhecimento pessoal e acadêmico em direção à homenageada, o que deixa inescapavelmente o sentimento encapar a tônica da escrita.

Assim sendo, no primeiro eixo, o político e o jurídico, encontramos cinco contribuições. Na primeira, Materialidades do invisível. Democracia, mídia e tecnopolíticas da vigilância, de Mónica Zoppi-Fontana, nos deparamos com uma reflexão selecionada com delicadeza, amabilidade e memória; a autora traz ao público um texto que resultou de sua participação, ao lado de Lagazzi, em uma mesa redonda realizada em 2011, por ocasião de um evento temático na Universidade do Estado do Mato Grosso (UNEMAT) encontro, segundo a mesma, tomado por afetos. A escolha, ajustada aos propósitos da coletânea, destaca a relação de afetividade materializada no encontro da mesa-redonda, bem como no atravessamento de duas trajetórias intelectuais. Da discussão empreendida por Zoppi-Fontana, aludimos ao cuidado em seu objetivo de analisar a produção da visibilidade em governos ditos democráticos. Para tal, a autora se debruça, principalmente, por romper as barreiras da opacidade e das interpretações que foram postas em circulação em relação à foto dos membros do governo Obama (e o próprio) assistindo, em uma sala, a execução de Osama Bin Laden (morto em 2011). Considerando o fato como um acontecimento, Zoppi-Fontana descreve e chama atenção à formulação da imagem e dos olhares que são produzidos a partir/por/com (d)ela. O afinado gesto de intepretação da autora convoca o leitor a reavaliar o olhar e o imagético, colocando em dúvida o modo como somos capturados pelas lentes, pela democracia e pelo regime de visibilidade.

Na continuação, José Horta Nunes nos brinda com Discurso de divulgação arquitetônica para o grande público: cotidiano e autoria. Logo no início, o autor chama a atenção para a capacidade de Lagazzi em seu "[...] modo de colocar questões originais, ajustar o método e chegar a formulações próprias, deslocando pelo esforço teórico aquilo que lhe servira de base para a análise" (NUNES, 2019, p. 49). Nesse tom, Nunes produz uma análise que considera um dos primados teóricos da homenageada: o cotidiano. Sua proposta procurou estabelecer uma interlocução entre o discurso cotidiano e a autoria no discurso de divulgação científica, mais especificamente o discurso de divulgação arquitetônica. A análise empreendida tem como base, especialmente, um livro de introdução à arquitetura, cujo público alvo são leitores não especializados, isto é, leitores sem conhecimento técnico da arquitetura e suas formas de compreensão científica do espaço, da construção, do desenho, da projeção. Nunes opta por ancorar sua proposta descritivo-analítica em outra noção também suscitada nos trabalhos de Lagazzi, a autoria. Desta forma, o pesquisador produz uma precisa análise que consegue dar visibilidade a mecanismos que compõem a formulação do discurso de divulgação científica. Nesse sentido, conforme Nunes, a arquitetura (no material analisado) é posta em cena como conhecimento que se tenciona entre a normatividade do discurso didático e o apagamento das condições próprias ao discurso considerado científico, dentre elas, a autoria. Na cena do cotidiano, a arquitetura e seus pressupostos passam a ser proeminentes de formações imaginárias.

Fernando Felício Pachi Filho, por sua vez, assina Liberdade de expressão e o mundo do trabalho: entre o direito e a utopia. Partindo de entrevistas realizadas com trabalhadores de diferentes empresas (indicados, inclusive por essas), Pachi Filho recorta do arquivo (constituído em uma pesquisa mais ampla) sequências discursivas que o permitem perseguir seu principal objetivo: compreender a produção de sentidos sobre liberdade de expressão no discurso dos trabalhadores. Como bem demonstrou o pesquisador, os dizeres que constituem o sítio de significância "liberdade de expressão" são marcados pela indecisão e pela vacilação em sua formulação, isto porque os entrevistados oscilam no gesto de dar forma à memória discursiva da liberdade, acarretando na profusão de lugares discursivos acedidos no ato de enunciar o tema. O autor também deixa claro o modo como o discurso liberal, associado ao jurídico, torna evidente o discurso de liberdade de expressão, significado, sobretudo, a partir do apagamento da determinação do político e atado ao juridismo - conceito próprio de Lagazzi. 
Na sequência, Gritar, denunciar e resistir: "como mulher, como negra", de Rogério Modesto, traz à tona a tensão racial como modo estruturante das relações sociais. As palavras de homenagem à Lagazzi, proferidas pelo autor, tornam-se importantes na medida que destacam que a pesquisadora teve um papel decisivo em sua formação, sobretudo, na constituição de formas de escuta, como a que mobiliza em seu texto. Em sua análise, o pesquisador se pauta no caso de Valéria Lúcia dos Santos (autora do enunciado que compõe o título), advogada que teve o direito de exercer sua posição como advogada interditado e cerceado. Modesto privilegia recortes que descrevem a situação vivida por Valéria face à impotência e à impossibilidade de encontrar, no interior do próprio sistema jurídico, o suporte do Direito - sistema esse que ao invés de ampará-la, termina por excluí-la de seus direitos. Vítima de uma intervenção violenta do aparato jurídico e da força policial - a advogada foi algemada e arrastada à força para fora da sessão que participava -, Valéria repete (aos gritos) que possui o direito de trabalhar "como mulher, como negra”. Assim sendo, Modesto explora a produção material do grito, que no caso de Valéria, entrelaça a denúncia social (feminina, racial) sobreposta a uma série de memórias discursivas que amparam as práticas racistas em nossa formação social. O autor demonstra com propriedade a contradição posta em jogo na formulação do grito de Valéria, via que possibilita a emergência contingente da resistência simbólica.

Último artigo do primeiro eixo, Comunistas, terroristas, vagabundos: a materialidade de comentários em vídeos do canal da comissão da verdade, de Silvia Regina Nunes, se explora o discurso produzido em condições de produção digitais sobre mulheres vítimas de tortura durante o período da Ditadura Militar Brasileira. Partindo de uma pesquisa anterior, Nunes preza pela escolha de vídeos da página da Comissão Nacional da Verdade (CNV) no YouTube. Mais precisamente, a autora privilegia a análise de comentários produzidos em um dos vídeos, no qual há o testemunho feminino da dor, do sofrimento e da brutalidade da tortura. Com vistas ao discurso de ódio, a autora aponta para uma não coincidência do que é dito no testemunho da vítima com o que é produzido como réplica pelos sujeitos internautas nos comentários do vídeo. A pesquisadora é incisiva na produção do gesto de interpretação, que explora os comentários - a maioria, propagando discurso de ódio e uma completa indiferença ao relato da vítima -, ao passo que desvela as formas de constituição, formulação e circulação de tais réplicas no corpo do digital.

A segunda parte, a imbricação de diferentes materialidades significantes, conta com cinco artigos. Pedro de Souza começa a seção com Arquivo e memória da voz: o caso Elis Regina em cinebiografia. Partindo de sua pesquisa sobre documentários cinebiográficos, Souza privilegia um estudo sobre a voz cantada. Para esse fim, parte do filme Elis: o filme (2016). Valendo-se da voz cantada de Elis Regina como centro da análise, o pesquisador explicita a covalência entre a sonoridade e o imagético na produção da espessura fílmica. Também retraça os modos como o espectador se expõe à narratividade fílmica, num pêndulo tenso entre canto e fatos da trajetória da cantora. O gesto analítico preconizado por Souza possibilita compreender a voz cantada em seu poder vocal e de formulação discursiva.

Nádia Régia Maffi Neckel, em A(s) provisoriedade(s) do ATOS, põe em questão a materialidade fílmica a partir do modo de formulação e constituição do filme ATOS: título provisório (2017) - trata-se de um filme de 11 minutos que confronta a vivência do feminino com o/no social. Circunscrevendo sua questão no entrecruzamento com o discurso artístico, Neckel dirige sua análise a partir da posição-sujeito encarnada nas personagens, aliando-se também a categorias que a permitem explorar a formulação fílmica, como o sujeito-da-câmera e o eccentric subject. A análise empreendida pela pesquisadora considera teorizações anteriores, que a possibilitam depurar a imagem e a narratividade do des-bordamento fílmico em sua opacidade. A trajetória analítica encetada por Neckel conduz o leitor à inquietude, posto que o tom, os enquadramentos e os enunciados encarnados na tela pelas personagens suscitam um profundo questionamento do ser mulher em nossa conjuntura histórico-jurídica, uma vez que pela língua e pela história se faz prevalecer enunciados, modos de se significar e lugares destinados ao feminino.

Em seguida, Pode uma imagem falhar? O funcionamento promissivo em diferentes materialidades significantes, Liliane Souza dos Anjos produz uma análise apurada em torno do funcionamento discursivo da promessa, tomando para tal imagens e discursos ao redor da relação entre Estado e favela; a autora, sobretudo, detém-se nas "promessas" do projeto de pacificação posto em marcha nas favelas do Rio de Janeiro em 2008. O caminho seguido por Anjos considera diferentes materiais de análise (em especial, paralelos históricos) para explicitar o efeito do jurídico, dos instrumentos normativos e do Estado no esvaziamento da promessa em seu potencial pragmático e discursivo. 
Por sua vez, Janaina Sabino com Entre os sentidos da metonímia e da metáfora, a resistência ecoaa... faz uma efusiva defesa à possibilidade de, em AD, a imagem possuir um lugar fecundo na prática teórica e analítica. Analisando uma exposição de quadros de autoria da artista brasileira Rosana Paulino, Bastidores (1997), Sabino destaca a formulação do visual entre o batimento da metáfora e da metonímia. Os quadros expostos, retratos de mulheres negras com alguns órgãos (boca, garganta) bordados em linha negra, permitem deslumbrar a produção imagética a partir de gestos que se produzem no artístico, no corpo da imagem e na instância social - cabe destaque à tensão racial e à história dos sujeitos negros que se tecem junto à arte do bordado. O bordado, desta forma, é encarado como meio simbólico de tecer a memória em fios de lã, pontos de costura e acabamentos finos que, no olhar de Sabino, estabelecem no fio do discurso silêncios, emoções e histórias que são estampados na pele e nos rostos das mulheres retratadas.

Por fim, fecha a seção Fernanda Moraes D’Olivo com Senso comum enquanto efeito de sentido: argumentação e contradição do/no social na poética do cordel. Decorrente de sua investigação de doutorado, D’Olivo explicita a produção do efeito do senso comum no Cordel. Entendo-o como materialidade significante, a autora encontra nos textos de Lagazzi, especialmente em O desafio de dizer não, um caminho para analisar sua questão. Seu material de análise, um cordel chamado Dilma Rousseff já é presidente da Nação (2011), de autoria do poeta Bule Bule, abre margens para que D’Olivo demonstre os mecanismos imaginários que se produzem justapostos às afirmações enunciadas no cordel. Atenta ao social, D’Olivo compreende um jogo argumentativo que, pelo poético, reafirma lugares comuns e consensos imaginários.

O último eixo do livro, resistência simbólica, possui três contribuições. A primeira, "Mas nessa luta se aprende. Se aprende muitíssimo". Testemunho de resistência. Memória, de autoria de Bethania Mariani, coloca em cena uma delicada e comovente análise a partir do enunciado "nessa luta se aprende". O enunciado, pronunciado por um pai que perdeu seu filho em 2014, na chacina de Iguala, México, passa a compor o trajeto de interpretação de Mariani. A autora ancora-se na noção de testemunho para, de modo brilhante, explorar o relato do pai que, reivindicando-se como representante das famílias acometidas pela morte trágica dos 43 estudantes, produz palavras, sentidos e sentimentos que confrontam o silêncio, o social e a memória. Nessa direção, Mariani demonstra o papel do Estado, da memória e do testemunho na composição do relato do pai que se formula como testemunho de resistência, atestando a possibilidade de, na língua, o sujeito ressoar o que se tenciona ao esquecimento.

Em seguida, Fábio Ramos Barbosa Filho escreve Espectros do Anexo 3. Rememorando uma discussão que teve com Lagazzi, Barbosa Filho redige um texto elucidativo em torno do Anexo 3 e dos primados althusserianos que rondam a famosa "retificação" de Pêcheux, presente na obra Semântica e Discurso: uma crítica à afirmação do óbvio. Por consequência, nesse caminho, o pesquisador também alude à constituição epistemológica da análise de discurso. Recorrendo a textos de Althusser, Barbosa Filho busca explicar, a partir deles, conceitos, ideias e posições que coadunam à compreensão do Anexo 3. De modo ilustrativo, o autor proporciona ao leitor uma valiosa leitura do texto pecheutiano, oferecendo direções a todos aqueles que são tocados pela "retificação".

O encerramento parte de Mirielly Ferraça com Pela elipse os sentidos transbordam: fissura na língua e movimento do sujeito. Iniciando com um relato de admiração à Lagazzi, Ferraça borda uma reflexão em que a resistência simbólica é posta como questão central. Encontrando em Lagazzi seu apoio teórico, a pesquisadora investe analiticamente em recortes de um corpus constituído pela própria em 2016 e 2017, no qual fazem parte entrevistas de moradores, trabalhadores e comerciantes do Bairro Itatinga, localizado em Campinas - SP. Notadamente conhecido na cidade como região de prostituição, o Bairro Itatinga passa a ser o foco das atenções de Ferraça. Das entrevistas, a pesquisadora recorta a formulação "casa de família" e explícita o funcionamento da elipse no modo como os dizeres dos entrevistados (em especial, os usos de "casa") se chocam com sentidos que emergem com a falta do complemento adnominal "de família". Assim, abre-se, conforme a autora, brechas para que diferentes memórias discursivas se tencionem no fio do discurso. As formas de "resistência simbólica" são exploradas por Ferraça, que destaca o papel do bairro na constituição de laços que transcendem o estigma social.

Ao fim, O discurso nas fronteiras do social - volume 2 presta-se à ilustre tarefa de homenagear Suzy Lagazzi. Suficientemente conhecida no círculo da Análise de Discurso que se configura em torno de Michel Pêcheux, a pesquisadora ao longo de décadas deu forma, alento e frescor ao modo de compreender o discurso, residindo aí sua implicação particular com o social e com a escuta às margens e aos desterrados às bordas de nossa formação social. Não há como falar de Lagazzi sem destacar sua reflexão sobre o 
cotidiano, o equívoco, o imagético, a materialidade significante e, por que não, também do afeto. Os textos presentes no volume imbricam afeto e fazer teórico, dando a entrever que o conhecimento também se produz nos delicados gestos da convivência, nos desapercebidos olhares cotidianos e nos singelos laços de amizade que tornam o fazer a Análise de Discurso, um ato convidativo. A proposta dos organizadores é cumprida com coragem, ânimo e genialidade. Fica patente a influência de Lagazzi na escrita, na formação e do estabelecimento de espólios teóricos e de parcerias que luzem intensamente com o tempo e com a singular presença do discurso no Brasil.

\section{(ㄷ) (1) $\circledast \circledast$}

Recebida em 10/01/2019. Aceita em 30/03/2019. 